\title{
Building Research Capacity in BRICS and Beyond: Lessons from the International Community
}

Dr Ewelina Kinga Niemczyk ${ }^{\dagger}$

\section{Abstract}

Research capacity building and research productivity are essential to the economic flourishing of any nation. Over the past decade, innovation and investment in research and development in BRICS countries - especially India and China - have strongly contributed to their economic growth. The scholarly literature shows that the five-member states have high numbers of (a) university graduates - especially in the fields of engineering and computer science - and (b) research outputs - mainly quantitative. The issue, however, is that the quality of BRICS graduates is sometimes questionable, and the nations are not considered as relevant global players when it comes to the research impact factor. To that end, it is essential to align quantity with quality in BRICS' higher education institutions. As growing economies, BRICS need to increase their investment in higher education and research capacity building to maximise their economic prosperity. Researchers who are knowledge producers and innovators can be considered the foremost role players in transferring university research to society. Therefore, investing in quality development and support is of the essence. This article is based on the voices of 32 international scholars affiliated with the Comparative Education Society in Europe. The respondents shared their views via an open-ended survey about: (a) the development of globally competent researchers; (b) the expectations placed on present-day researchers; and (c) the demands researchers face in terms of research productivity. The findings indicate that, regardless of the context, researchers are confronted with similar demands, namely: to secure funding; engage in international and interdisciplinary research projects; and produce tangible outputs. It is also evident that research capacity building at respondents' respective institutions needs enhancement in order to align with the current research demands.

Keywords: Research Capacity; Research Productivity; Globally Competent Researchers; BRICS Countries; International Qualitative Study

\footnotetext{
${ }^{+}$Professor, Education and Human Rights in Diversity Research Unit North-West University, South Africa, Email: ewelina.niemczyk@nwu.ac.za (C) 2020 Niemczyk. This is an Open Access article distributed under the terms of the Creative Commons Attribution License (http://creativecommons.org/licenses/by/2.0), which permits unrestricted use, distribution, and reproduction in any medium, provided the original work is properly cited.
} 


\section{Introduction: Research Capacity in BRICS and Beyond}

Research capacity building and research productivity are essential to the economic development of any nation. The pressures associated with globalisation and drive toward a competitive and dynamic knowledge-based economy forced governments and institutions across nations to enhance their existing research infrastructure, invest in the development of future researchers, and formulate relevant policies. The competitive global environment forces nations to improve quality and excellence in their respective higher education systems and get a favourable position in international rankings.

BRICS countries comprise five growing economies: Brazil, Russia, India, China, and South Africa. Over the past decade, innovation and investment in research and development have contributed to the economic growth in the BRICS member states, especially India and China. In fact, as reported by Reddy (2018, para 1 ) in the article for the Institute for New Economic Thinking "[s]ince 2008, the five BRICS countries have accounted for fully 56 percent of global growth (and the developed countries for only 22 percent)". The five-member states are recognised for their significant landmass, natural resources, production as well as consumption. The member states - notably Brazil, Russia, India, and China - also play a key role in supplying technical labour.

The scholarly literature shows that the fivemember states have high numbers of (a) university graduates - especially in the fields of engineering and computer science - and (b) research outputs - mainly quantitative (Carnoy, 2012). The issue, however, is that the quality of BRICS graduates is sometimes contentious, and the nations are not considered as relevant global players when it comes to research impact factor. As articulated in Wolhuter's (2019, p 156) work exploring the authorship of Education research in Africa "the value of Education research is in the final instance located in its impact on practice". To that end, it is essential to align quantity with quality in BRICS' higher education institutions.

The World Development Report (World Bank, 1998) predicted that knowledge, not capital, would be the key to sustained economic growth. Indeed, as it was true then, it is now. The report mentioned above highlights two kinds of knowledge: technical knowledge, or simply know-how; and knowledge about attributes, that is, knowledge about products, processes, or institutions. The unequal distribution of technological knowledge across nations and the associated challenges with closing the gap is also underscored: "[c]losing knowledge gaps will not be easy. Developing countries are pursuing a moving target, as the high-income industrial countries constantly push the knowledge frontier outward. Indeed, even greater than the knowledge gap is the gap in the capacity to create knowledge" (p. 2). To that end, it is essential to recognise that knowledge is often costly to create; therefore, developed countries mostly lead the way in knowledge production. Nevertheless, over the past years, innovation in emerging economies has been remarkable, contributing significantly to the overall economic growth of nations.

The BRICS Think Tanks Council report (2017, p. 85 ) indicates that scientific and technological developments are positively associated with BRICS' growing productivity. Indeed, BRICS countries show considerable progress in their science, technology and innovation input and output indicators. For instance, Brazil and India have doubled their number of scientific and technical publications between 2000 and 2009, while China quadrupled the number of its publications during that time. This increasing number of publications results in significant participation of the BRICS countries in the scientific production of areas such as material sciences, chemistry and physics. The Thomson Reuters Web of Science database shows that the BRICS member states' research productivity is growing. Between 2008 and 2011, they accounted for $15.5 \%$ of all published articles, 
which is impressive, considering that the countries represent the Global South.

Sesay, Yulin, and Wang (2018) conducted a study to determine the relationship between the national innovation system and economic growth in the BRICS member states. Their findings illustrate that developing a national innovation system in "BRICS economies is exceptionally crucial in advancing a constructive approach for promoting sustainable growth in emerging economies ... increasing the role played by universities, governments and businesses will eventually lead to an increase in economic growth." (p. 9)

In a similar way, Freeman (1982) argues that technological advancements and innovation at large are central to economic growth and the overall development of any nation. Sesay et al. (2018), seemingly asserts that innovation is a "collective effort that needs a different set of knowledge resources and know-how. As such, different countries will have different capabilities for innovation" (p. 2). Indeed, it is arguable that the extensive scholarly literature investigating the relationship between innovation and economic growth of a nation shows different results for different nations.

Although the BRICS member states have shown economic growth, they are currently struggling to maintain the same pace of robust economic growth. According to Bilbao-Osorio (2014), in order to maintain stable growth, the BRICS nations need to enhance their education system along with research productivity and innovation. This would include (a) investment in information and communications technology, and (b) interaction between research institutions and local companies.

Similarly, in their article, Meyer and Nascimento (2014, p. 13) bring attention to the research capacity in the BRICS countries. For instance, the authors explored whether higher education institutions prepare highly skilled researchers. They report that "competitiveness in a global economy based on innovation and knowledge demands [an] advanced capacity to produce highly-skilled, particularly technical, workforce" (p. 4). In addition, Meyer and Nascimento (2014, p. 12) investigated in which specialisation each member state performs best in terms of research productivity. Their findings portray the strengths of each of the BRICS countries.

Brazilian scientists are much more influential in Physics, Mathematics and Engineering, although their output is very small in these subjects. Citations to Russian papers are by far concentrated in Multidisciplinary studies, not in Physics nor in Geosciences, the top publishing areas in terms of quantity by scientists based in Russia. India is relatively strong in Engineering, China in Mathematics and Engineering. South African scientists are more cited in Microbiology, Immunology and Clinical Medicine, revealing a relative strength of this country in Health sciences in general (Meyer and Nascimento, 2014, p. 12).

Wolhuter (2008) investigated authorship in the field of Comparative and International Education. He analysed 1157 articles published in the Comparative Education Review during the first 50 years of the journal's history. The findings revealed that throughout that time, the majority of publications came from the United States of America, accounting for more than 50 per cent of overall outputs. The United Kingdom, Canada and Germany followed the United States.

Without a doubt, higher education institutions are under constant pressure to increase their research productivity and research-related revenues in order to become competitive players in the international research arena. Therefore, institutions pursue strategies for building research capacity, at times compromising quality teaching as well as community service. Although the number of BRICS publications is significant, the literature informs that they are not relevant global players in terms of impact (Meyer \& Nascimento, 2014). It seems that research productivity is mostly numerical; however, the quality relevance is not clear at this point.

Despite the crucial role of research capacity building in knowledge production and economic 
development, not enough attention has been dedicated to it in the BRICS countries. Therefore, this study explores research capacity in the BRICS member states and beyond in order to interpret the current state of research activity internationally and the areas that call for attention. The study is informed by an international literature review and perceptions of international respondents about (a) the development of globally competent researchers; (b) the expectations placed on present-day researchers; and (c) the demands researchers face in terms of research productivity.

The next section provides an overview of literature specific to the five-member states, with particular attention to (a) research investment and funding, and (b) researchers and research productivity. After that, the qualitative research methodology is described. Subsequently, the results of the study are provided along with references to the relevant scholarly literature. Lastly, final remarks are made to provide concluding ideas and recommendations.

\section{Zooming in on BRICS Member States}

The role of BRICS higher education in a knowledge-based economy is of the highest importance. Universities are expected to produce new knowledge in order to address societal issues and promote innovation. It is undeniable that investment in research is necessary to achieve expected research productivity or activity.

\section{Investment in Research and Development}

Over the past decade, innovation and research capacity building in the BRICS member states has contributed to their economic growth. All the BRICS nations have maximised their investments in research and development as well as developed collaboration between universities, governments and businesses. It is essential to recognise that universities play a central role in conducting research, developing future researchers, and producing tangible research outputs.

According to Odhiambo and Ntenga (2015, p. 283), despite the crucial role that research plays in knowledge production and economic development, the necessary research investment has not been made by African countries. In fact, most developing countries remain knowledge consumers instead of knowledge producers. South Africa is one of the developing countries that has made a significant investment in research and development. As a result, South Africa is ranked first in Africa based on its total expenditure on research and development. The authors mentioned above point out that, although South Africa's total gross expenditure on research and development, as a percentage of gross domestic product (GDP), is the highest in Africa, it is still lagging behind other member states, especially when compared to that of China, Russia, and Brazil.

The South African government has made different investments to strengthen the research capacities of academics, in particular those that were previously disadvantaged. One such initiative is the Thuthuka Programme, which is part of the Human and Institutional Capacity Development directorate of the National Research Foundation (NRF). The goal of this programme is to: (a) enhance the qualifications of participating researchers to doctoral and postdoctoral levels; (b) accelerate their progress in the mainstream national and other research support opportunities; (c) contribute to sustainable development, and (d) increase the number of NRF-rated researchers. Besides, the NRF has also implemented a mentoring programme, which interacts with mentees who form a large population of South Africa's academia.

Over the past two decades, Brazil has enjoyed good standing in South America in terms of investments in its research capacity. In fact, "since 2008 [Brazil] has occupied [the] 13th place for scientific production at the global level, overtaking countries with a far greater tradition in research and trainng of human resources, such as the Netherlands, Switzerland, Sweden, Belgium, Denmark and Israel" (Grochocki, Guimarães, Prata, \& Oliveira, 2018, p. 43). As reported by scholarly literature, Brazil 
committed financially to invest in science and technology in order to maximise its potential in research productivity.

Regarding South Africa, Odhiambo and Ntenga (2015) report that the business sector and the government are the main funders of research and development in the country. The government provides funds for basic research, which is conducted to advance knowledge. Meanwhile, businesses are willing to provide funding for applied research that can materialise and make an impact on society, which leads to discoveries. It is also important to add that businesses' investments are highly driven by financial gains based on scientific discovery. The fundamental difference between the government and business sector funding is their expectation of results - tangible assets versus intellectual work.

Brazil's funding also comes from both sources (government and business sector); however, the interaction between universities and the business sector leaves much to be desired. In fact, the funds from businesses are scarce and result in small registration of patents in the country. Attention is directed to the academic community in terms of research and innovation supported by the government. As accurately stated by Grochocki et al. (2018, p. 44), in the American model, "national laboratories receive from the respective supervising departments and research development missions that are already in line with companies, resulting in technological products that are of national interest and very often procured by the government itself. This culture of integrated research programs is almost non-existent in Brazil."

India is considered an economic powerhouse. Research in India is also funded by both the public and private sectors. In February 2018, a $10 \%$ raise was announced in the country's science spending to INR 536.2 billion (US\$8.4 billion) for 2018-2019 (Jayaraman \& Priyadarshini, 2018). The head of the government's funding agency called the Department of Science and Technology, Ashutosh Sharma, stated that the funds for research doubled in 2017-2018 as compared to investments made in 2014-2015. It is also important to note that in terms of the number of researchers and technicians engaged in research and development (R\&D) activities, the number of researchers in India is much smaller compared to China or Russia.

According to Wang (2019), the Chinese government is developing a new funding programme called the "double first-class" plan, which features performance-based funding as a central pillar of government funding. The allocation of funding to higher education institutions to stimulate their research productivity has always been an issue with economic relevance. Wang (2019) highlights the fact that many nations (including some BRICS nations) have embraced the performance-based funding method to allocate research funds because of public pressure for efficient use of taxpayers' money and demand for transparency as well as accountability.

China's public universities rely heavily on government funding to support their research efforts. A substantial portion of the government fund is distributed through special funding programmes targeting selected universities. The most notable funding programmes are the "211 Project" and the "985 Project" (Wang, 2019, p. 66). These programmes are meant to enhance the research capacity of the Chinese universities to become internationally competitive. Wang (2019) reports that the main criticism of the financial support provided by these projects is that the selected universities they fund to increase their research productivity are not performing better than the universities with fewer research funds.

Furthermore, in some cases, the institutions that receive support were found to have misused research funds. In response to this situation, the Chinese government is introducing the "double first-class" plan. This fund is conditional on performance. Therefore, when the university receives the funding and does not deliver the tangible outputs, the funds might be adjusted or even annulled. 
China is considered an industrial superpower, especially in manufacturing sectors such as pharmaceuticals and artificial intelligence (Belay, 2018, para. 6). The Chinese government made a significant investment in research and innovation, strategically developing the education system and local manufacturing through research and industry collaborations at national and international level.

... China's heavy investments in research and innovation with both local and foreign companies and universities. The power of this growth is the result of efforts made by the Chinese government to optimize the flow of knowledge from basic research to application in the marketplace. The newly modified structure of the national funding agencies and regulatory commissions has streamlined the process of publishing research and translating it into viable market products, making it increasingly easier for Chinese researchers to advance their research and economic activity while still competing on traditional academic metrics (e.g., publications, citations, journal impact) (Belay, 2018, para. 6).

According to Kolachi and Shah (2013), the Russian government has been highly active in building a culture adaptable to BRICS activities, providing education with significant investments that foster intellectual capital development. Overall, the Russian government is striving to make its universities number one by investing in R\&D.

\section{Researchers and Research Productivity}

According to Minch (2013), the research capacity and performance of a nation can be assessed by: (a) input measures, such as the number of trained personnel carrying out research and development work and the level of national expenditure on R\&D; and (b) output measures, such as the number of scientific and technical articles published, patents filed, revenues from royalties and licenses, and use of high technology. In line with the above, Wang (2019, p. 67) claims that "the most commonly used measures to capture the research outputs include the number of research publications, research capability rating, citation or impact of publications, number of patents, and knowledge transfer activities. The generation of research output requires various inputs such as professors, graduate students and funding."

As indicated by Global R\&D Funding Forecast (2017), over the past 15 years, Brazil has been ranked among the ten largest economies in the world. Cross, Thomson, and Sinclair (2017) indicate that Brazil is the 13th largest producer of research publications globally. As regards citation impact, Brazil has historically been below the world average, but over the past years, the numbers have increased by more than $15 \%$. The visible research productivity shows in fields that receive substantial investment, such as environment, psychology, or mathematics. Their success is evident in the citation impact, which is almost comparable with the world average.

Noteworthy, internationally recognised scientific development in Brazil is mainly due to research production of universities. As reported by Grochocki et al. (2018, p. 43), graduate courses "generate thousands of dissertations and theses per year (in 2015, there were around 55,000 master's dissertations and 18,000 PhD theses), certainly adding to Brazil's internationally acknowledged scientific production." The question that is often entertained, is to what extent the quantity aligns with the quality of the outputs. Quality is the most essential factor of sustainable development of the national economy as well as its integration into the world economy (Zinurova et al., 2016, p. 204).

Regarding quantity mentioned above versus quality of outputs, Bitzer (2009, p. 431) argues that there is a lack of appreciation and recognition, as well as power-authority relations, in higher education. He states that some academics and researchers put minimal effort into scholarly work to produce reliable and valid research. He calls for authority in higher education research, with the firm belief that this 
would provide recognition activities within the field.

Considering research outputs, South Africa precedes other African nations. Yet, comes short comparing to other nations outside the African continent. As indicated by Wolhuter (2019, p. 144), low scholarly outputs in Africa are due to the small size of the higher education sector, qualifications of staff in African higher education, limited funding as well as the availability of resources dedicated to research and research leadership. Zooming on South Africa, Wolhuter further reports that there is a lack of scholarly South African publications in social sciences, especially the field of Education, which in turn limits the enhancement of education system including the actual teaching practices.

Rajan, Swaminathan, and Vaidhyasubramaniam (2018) claim that, over the past years, the publication output from Indian institutions has been steadily increasing, which can be attributed to the higher investment in research and connection of the number of publications with career advancement. The authors admit, however, quantity has taken over the quality aspects in measuring the scholarly output of institutions.

It is essential to note the presence of predatory journals that have become part of the scholarly research outlets. Predatory journal publishing is a successful illegitimate business that affects the BRICS nations. The scholarly literature also informs us that about $27 \%$ of the publishers of the fake journals and $42 \%$ of the fake single journal publishers are based in India (Prasad, 2015).

Panigrahi (2019) reports that recently, new alternatives were introduced as a form of resource generation by higher education institutions in India. These include "public private partnerships, research collaboration activities, intellectual property rights, philanthropic and alumni contributions, foreign universities' participation through student and faculty exchanges, and corporate sector participation in higher education" (p. 41). Gupte (2015, p. 24) proposes that the immediate need in India is to encourage industry-academia collaborations, promote collaborations between the universities and the public authorities as between the government and R\&D laboratories and also increase the number and quality of doctoral students:

Indian system of education is characterized by a number of constraints and research is one of the main ones. Carrying out Research in India has a number of challenges such as [the] absence of intellectual stimulation, emphasis on rote learning, lack of scientific theory and base, inadequate data, lack of scientific knowledge, and training in Research Methodology. In the globalized world, it is imperative to have knowledge-driven growth powered by innovation. A number of steps could be implemented to foster research such as industry-academia collaboration, development of vocational skills, provision of more funds and inclusion of research as a criterion for faculty promotion. India has a well-acclaimed Brain Power, and promotion Research will only help India move up the global intellectual ladder (Gupte, 2015, p. 21).

China maintains effective internal coordination with other BRICS states. China is self-sufficient, with highly-skilled engineers and policymakers, who are needed by many countries. Xie and Freeman $(2019$, p. 2) explain that China has shifted its economy toward markets, joined the global economy and expanded its higher education sector. As regards research productivity, the above-mentioned authors provide evidence of China's high contribution in terms of scientific publications:

China's contribution to global science based on the quantity and quality of Chinese articles in physical sciences, engineering and mathematics journals relative to the total number of articles in those journals. The major finding is that, when properly measured to take account of articles authored by Chinese researchers at non-Chinese addresses as 
well as of China-addressed articles in the Scopus database, and of articles in Chinese language journals not in the Scopus database, Chinese contributions account for 36 percent of global scientific publications. This is approximately twice the standard address-based measure of papers in international scientific journals and a comparable share of global scientific citations (Xie and Freeman 2019, p. 2)

In their research, Gazizova, Panfilova, and Makarova (2016) discuss the concept of excellence, which, according to them, is connected to "rankings movement" resulting from the competitive higher education landscape and overall competitive global environment:

...the excellence is by and large related to world-class research because knowledge society and economy stresses the role of scientific and technological research as the main key for innovation-based competitiveness...Enhancing research performance and internationalization become the essential directions in achieving such indicators as: the number of publications per faculty member in journals indexed by Web of Science and Scopus; an average citation rate per faculty, based on unique publications in Web of Science and Scopus; the proportion of international faculty, including international PhD holders, etc. (Gazizova et al.,2016, p. 584).

In order to stay globally relevant, many Russian higher education institutions engage in research projects connecting universities and business sectors, establish research labs, and invest in modern scientific infrastructure. In fact, in recent years, significant progress has been made in developing and strengthening Russian higher education. However, the scholarly literature emphasises that Russian universities should intensify research productivity to keep up with global research activity. Based on a survey of faculty research in Russia, Smolentseva (2015, pp. 6-7) states that the higher education system is far from achieving an appropriate level of research activity:

The publication records of faculty reflect low levels of research activity. In the previous three years, 58 percent of faculty had not published any articles in Russian refereed journals, and another 29 percent had published only one or two articles. Furthermore, 8 percent published at least one paper in a foreign refereed journal (Smolentseva, 2015, pp. 6-7).

Smolentseva outlines the following three factors that prevent universities in Russia to become research productive: allocation of research mostly to research institutes; inadequate government funding of universities; and limited opportunities for faculty to raise research funding directly. She believes that, until these limiting factors are not addressed, Russia will not develop an appropriate level of knowledge production at universities.

As stated earlier, research capacity building and knowledge production are essential to economic development, yet not enough attention has been devoted to it in the BRICS member states. This research explores research capacity in the BRICS member states and beyond in order to interpret the current state of research activity internationally and the areas that call for closer consideration. The following sections describe the methodology and data collection method employed to gain the desired insights into the area under investigation.

\section{Methodology}

This is an interpretive qualitative research study where "meaning is disclosed, discovered, and experienced. The emphasis is on sense-making, description, and detail" (Given, 2008, p. 465). Orlikowski and Baroudi (1991, p. 5) explain that:

Interpretive studies assume that people create and associate their own subjective and intersubjective meanings as they interact with the world around them. Interpretive researchers thus attempt to understand phenomena through 
accessing the meanings participants assign to them.

Meaning-making of the respondents' perceptions have proved an important source of insight into current realities related to research capacity and research productivity. The collected data show: (a) the development of globally competent researchers; (b) the expectations placed on present-day researchers; and (c) the demands researchers face in terms of research productivity.

Before data collection, the ethical requirements were met through securing ethical clearance from the South African institution leading the project. The qualitative research data were collected in mid-2018 employing an open-ended questionnaire developed in Survey Monkey, a cloud-based software tool. The invitation, along with the link to the questionnaire was sent to all the members of the Comparative Education Society in Europe after securing the agreement of the conference organisers. The invitation message clearly indicated that participation was voluntary and that respondents would be anonymous. The respondents were assured that the information disclosed by them would remain concealed.

After receiving all questionnaires, the data were converted from the Survey Monkey software to an Excel file. After carefully reading all the responses, the data were analysed according to qualitative research methods (Patton, 2014). The responses were coded, grouped into categories that reflected the purpose of this research, thematically synthesised and interpreted. More specifically, the key themes were identified, addressing the development of globally competent researchers and the demanding research productivity environment. The final themes became the basis for exploring and sharing the findings.

The open-ended questionnaire was completed by 32 international respondents affiliated with the Comparative Education Society in Europe. The respondents represented 15 countries, including members of the BRICS nations (China, Russia, and South Africa). Most respondents
(72\%) were experienced researchers, and $71 \%$ of them were females.

In order to ensure the credibility of the data, respondents' verbatim quotes are included in the text (Roller \& Lavrakas, 2015). It is important to note that the findings of this study are not meant to be transferable to all settings but are informative.

\section{Findings from the International Community}

As stated earlier, the findings emerged from the data collected from 32 international scholars representing 15 countries, including members of the BRICS nations (China, Russia, and South Africa). The respondents shared their views about: (a) the development of globally competent researchers; (b) the expectations placed on present-day researchers; and (c) the demands researchers face in terms of research productivity. This section comprises two subsections: Global Competence and Research Productivity Requirements.

\section{Global Competence}

Respondents shared their views about the kind of competencies researchers need to have in order to engage in research activities inter(nationally). In this work, competency refers to abilities, understandings and skills that enable individual researchers to see themselves as globally competent. According to most respondents, the following are key competencies:

competence to understand local and worldwide issues, crises and approaches; competence to conduct research in different national and international settings; awareness of different sociocultural, academic and research traditions; knowledge about the principles of governance of the education policy and practice; ability to conduct and publish research that is of interest to researchers worldwide; ability to communicate with other researchers across nations and to develop relationships and cooperation networks; ability to work with people from diverse cultural and linguistic backgrounds; skills 
to exchange scientific ideas, theories, and methodologies; awareness of cultural and political sensitivities in other nations.

The following quotes illustrate respondents' perceptions of what it takes to be a globally competent researcher.

This means being open to theories and methodologies that are being used outside your own university or geographic location, using them critically, and finding linkages between different sets of theories and methodologies. It also means being able to situate research findings into current global development. (Novice Researcher, the Netherlands)

Mastering academic knowledge that is used in the international debate/research...having awareness about the 'issues' that concern humanity such as global warming, migration etc. I notice that for raising this awareness, I need to follow "western" media as well. in [sic] my country there are sometimes different "pertinent" problems. Developing and maintaining professional and non-professional relations. (Senior Researcher, Russian Federation)

Two respondents focused on the importance of considering socio-cultural differences and ability to interact with diverse cultures. This connects with the abilities and skills that were listed earlier with regard to competencies needed by globally competent researchers.

It means to be aware of different sociocultural and academic and research traditions as well as of the variety of institutional make-ups [sic] for education in different countries and regions of the world. At the same time, it also means to be aware that all of the above are linked and condition each other in many ways. (Senior Researcher, Italy)

It means [a] researcher is ready to conduct multicultural and multidisciplinary research in different places of a [sic] world and to use contemporary media in communication. A globally competent researcher has indepth knowledge and understanding of multicultural issues, and ability to work with people from diverse cultural and linguistic backgrounds, skills to exchange scientific ideas, reflections from theories, methodologies, research reports. (Senior Researcher, Poland)

Interestingly, two of the respondents claimed not knowing nor "giving too much thought" about what it means to be a globally competent researcher. One of them also added that " $[t]$ o be honest, I feel competent as a researcher only in the parts of the world where I have the expertise (East Asia and the UK)."

The responses from this study align with the scholarly literature (Niemczyk, 2018, p. 176) that provides emerging definitions for what it means to be a globally competent researcher.

A globally competent researcher possesses the knowledge, skills, values, and attitudes necessary to conduct respectful and rigorous research in diverse contexts. Globally competent researchers are aware of a wider world, critical global issues and their impact on education in different contexts. They are committed to collaborating within multicultural and multidisciplinary settings. Globally competent researchers value diversity, social justice, and manifest intercultural sensitivity conducting and reporting research.

The respondents also highlighted challenges to prepare the next generation of globally competent researchers at their institutions and beyond. The following list represents most frequently voiced challenges:

lack of funding and opportunities for emergent researchers to travel abroad; limited knowledge of international research; limited knowledge of foreign languages (including English); highly competitive nature to secure external funding (for research projects and international conferences); huge teaching workloads and associated lack 
of time; lack of mentors and supervisors who are globally competent; challenge to provide knowledge and skills to carry out international research studies; international and intercultural exchange; how to finance internationalisation.

The lack of funding to support researchers' active engagement in research and research communities is vivid in the following responses:

Globally, the challenges are: Funding and opportunities for emergent researchers to travel and spend study and research periods abroad, and in multicultural, multidisciplinary and multiperspectival environments. (Senior Researcher, Italy)

Work contracts are temporary; therefore researchers are constantly on the move, and therefore it is difficult for institutions to establish some sort of "stability" in terms of expertise, due to a lack of funding; this is all very challenging, especially for family life. Money is generally lacking in academia. (Novice Researcher, Germany)

\section{Research Productivity Requirements}

The respondents shared their views about the demands placed on researchers at their institutions in terms of research productivity. One of the most listed was the pressures related to publishing in top journals and securing funding for research projects. Other demands often defined by the respondents as pressures include:

partaking in collaborative, international research projects; writing multiinstitutional grant applications; coauthoring cross-disciplinary publications; supervising postgraduate students; showing an impact on research.

The voices of the majority of the respondents are well encapsulated in the words of a senior lecturer at an Australian University:

Research productivity is measured by a number of grant applications, PhD supervisions, publications, subjects delivered, courses (non-standard) delivered, money brought in, international collaborations, coauthored publications and multiinstitutional grants.

Referring to the feasibility of meeting the research productivity requirements, respondents were very vocal about clashes between teaching and research productivity requirements:

...research productivity contrast at times with teaching obligations, hence may provoke overwork, stress and burn out [sic]. In addition, the national \& institutional criteria and standards for research productivity tend to value a certain type of research, while devaluing other (Senior Researcher, Italy)

Several respondents highlighted the necessity to compromise personal time for professional productivity. To this end, scholarly literature shows that time is highly valued. Research productivity demands affect scholars' personal lives as well as the organisation of their working time (McGinn, 2012; Sparkes, 2007).

It can be difficult. Sometimes you would like to write on something, but you do not have the time to do it because administrative tasks, the search for money and new jobs consume a lot of time. (Novice Researcher, Germany)

Overall, the respondents agreed that meeting the requirements of research productivity at their institutions was not easy and depended on several factors. A South African professor expressed that the requirements are not fair and may lead to illness:

No, [the requirements are] not fair at all. Reason: most academics who take these instructions seriously, are getting sick/ill sooner than ever before in the history of mankind - especially cancer and cancerrelated illnesses.

In terms of factors influencing research productivity, accessibility to research funds was identified as number one. Scholarly literature shows that higher education institutions should 
support academics in accessing funds, which would imply expanding their research support services (Mullen, Murthy, \& Teague, 2008).

Of course is not easy - but it depends on the opportunities created within the institution - mentoring available, good supervision, existing collaborations and networks. In the current climate of funding being cut for higher education, all academics here feel that: we cannot afford research if it is not funded externally, we have to teach a huge number of students so the institution can pay our salaries (Senior Researcher, Australia)

A Senior Researcher from the United Kingdom said:

[o]btaining funding for research is very very [sic] difficult as all universities have had their funding cut, and they are all requiring their staff to put in bids for research.

Respondents also expressed their concerns about the quality versus quantity of research outputs. This connects to a scholarly debate over the effects of allocating university funding based on the number of publications. Many scholars argue that this type of approach not only rewards quantity over quality, but also promotes the mindset of doing more but not necessarily better (Lewis, 2017).

I consider the productivity demands a trick as the quality of the articles is really not revised. some [sic] academics write very descriptive articles and are not good researchers. Some of my colleagues are able to write articles but cannot write books. (Senior Researcher, Spain)

Also, according to a novice researcher from the Netherlands:

[i]n my previous department that was different [sic] and people were clearly more stressed about the work, and I believe this will eventually affect the quality of research, teaching and personal life.
In addition, the respondents also identified bureaucratisation, lack of mentorship, long peerreview processes and unnecessary timeconsuming meetings as factors preventing them from accomplishing the expected research productivity demands.

\section{Final Remarks and Future Direction}

It is evident from the findings that competencies expected from researchers and the research productivity requirements are growing. The overflowing demands and associated pressures influence how we should approach research capacity building in higher education institutions in BRICS and beyond. Research-intensive universities are characterised by a strong focus on research capacity, which leads to increased research productivity and innovation. Research productivity, in turn, leads to increased revenue and higher rankings of universities.

The empirical findings indicate that researchers are faced with increasing demands to secure funding, engage in international and interdisciplinary research projects, and produce tangible outputs. All the above-stated research activities call for specific competencies. If we consider research capacity building as a process meant to increase the ability of individuals and institutions to undertake quality productive research, then some questions emerge. For instance, how do we develop these competencies when (a) preparing novice researchers and (b) providing spaces professional development for senior researchers? How do we prepare globally competent researchers for highly competitive international research enterprise?

It is evident from the findings that research capacity building at the respondents' respective institutions needs enhancement in order to align with the current research demands. Based on the reviewed literature, this is also true for the BRICS countries. Although the BRICS member states already recognise the value of investing in research and development, there is a need to boost such investment in higher education and research capacity building to maximise their economic prosperity. Such investment does not relate solely to putting more money available 
but also to transparent allocation, responsible management, and accountability of such funds. Researchers who are knowledge producers and innovators can be considered the foremost role players in transferring university research to society. Therefore, investing in quality development and support is of the essence.

It is crucial to build awareness around the challenges to meet the research productivity requirements expressed by the respondents. Moving from awareness to action, the focus should be on how to eliminate, or at least ameliorate, these challenges. In regards to the struggle with research funding, higher education institutions need to consider expanding their research support services and assist researchers in accessing funds internally and externally.

Without a doubt, higher education institutions' policies, practices, and resources impact the productivity of the researchers. In order to assist universities to compete successfully in the international ranking hierarchies, there is a need to apply practical approaches along with growing efforts and recourses. Researchers are always faced with the competing demands of teaching and researching. As reported by the respondents, this, in turn, leads to overwork and lack of time to engage in both scholarly activities effectively. Researchers cannot be left on their own to manage and balance these demands. The institutions need to put in place practices that facilitate reasonable distribution of teaching and research load.

Another reported challenge was international and intercultural connections. BRICS are powerful in terms of collaborating and sharing knowledge along with best practices. Therefore, promoting active collaboration between BRICS universities, governments, business sectors and other stakeholders could maximise their research capacity.

The enhancement of research productivity can be stimulated by encouraging faculty members to join research units, which have the potential to support them in their research efforts. Such units, along with the faculties, should provide mentorship and infrastructure to maximise researchers' research outputs. It is crucial to keep in mind that excess of managerialism and bureaucracy can inhibit research activities. Building research capacity in an emerging research institution also requires evaluation of research management practices and identification of practices to promote the evolving research agenda. Also, performing systematic, research-based reviews to identify success areas and areas for improvement is of the essence.

As was stated earlier, research provides evidence that there is a positive relationship between innovation and economic growth. As a result, innovation has become a major factor when considering the economic growth of any nation. Understanding BRICS innovation potential and research capacity are important in order to evaluate how they can be enhanced and maximise contribution to economic growth. A knowledge-based economy is the key to longterm economic progress and well-being of the BRICS member states and beyond.

Future studies could investigate researchproductivity demands experienced by scholars in the five BRICS member states. The focus could also be directed towards research education, namely what practices and policies guide each member state in preparing the next generation of globally competent researchers.

\section{References}

Bilbao-Osorio, B. (2014). How are the BRICS reaping the technology dividend? World Economic Forum. Retrieved on November 2, 2019 from, https://www.weforum.org/agenda/2014/04/ict -building-block-growth-brics-2/

Belay, K. (2018). China is growing as a university research superpower. Here's how it could affect U.S. universities. Retrieved on January 10, 2020 from, https://eab.com/insights/expertinsight/university-research/china-is-growing-asa-university-research-superpower

Bitzer, E. (Ed.). (2009). Higher education in South Africa: A scholarly look behind the scenes. Stellenbosch: Sun Press. Journal of Student Affairs in Africa, 4(1). https://doi.org/10.14426/jsaa.v4i1.150 
BRICS Think Tanks Council. (2017). Realizing the BRICS long-term goals: Road-maps and pathways. Retrieved from http://sabtt.org.za/brics/long-term-strategyfor-brics/

Carnoy, M. (2012). Will the BRIC countries become the new centers of high tech production and innovation? A look through the lens of changing university systems. Retrieved from http://scid.stanford.edu/system/files/shared/d ocuments/Slides_Carnoy.pdf

Cross, D., Thomson, S., \& Sinclair, A. (2017).

Research in Brazil. A report for CAPES by Clarivate Analytics. Retrieved on April 4, 2020 from, http://www.sibi.usp.br/wpcontent/uploads/2018/01/Relatório-ClarivateCapes-InCites-Brasil-2018.pdf.

European Parliament. (2012). The role of BRICS in the developing world. Report of the Directorate-general for external policies. Retrieved on January 22, 2020 from, https://www.ab.gov.tr/files/ardb/evt/1_avrupa _birligi/1_9_politikalar/1_9_8_dis_politika/The _role_of_BRICS_in_the_developing_world.pdf

Freeman, C. (1982). Technological infrastructure and international competitiveness, Industrial and Corporate Change, 13(3), 541-569.

https://doi.org/10.1093/icc/ dth022

Gazizova A., Panfilova V., \& Makarova, O. (2016). Towards Excellence in Russian Higher Education Institutions. International Journal of Humanities and Cultural Studies. Retrieved from http://www.ijhcs.com/index.php/ijhcs/index

Given, L. M. 2008. Interpretive research. The SAGE Encyclopedia of Qualitative Research Methods: 464-467. Thousand Oaks, CA: Sage.

Global R\&D Funding Forecast. (2017). R\&D Magazine, Winter 2017. Retrieved on December 1, 2019 from, www.rdmag.com

Grochocki, L., Guimarães, J., Prata, A., \& Oliveira, J. (2018). Engineering and development in Brazil, challenges and prospects: a new perspective on the topic. Innovation \& Management Review, 15(1), 4157. doi: https://doi.org/10.1108/INMR-022018-003
Gupte, M. (2015). Role of research and higher education in India. Abhinav International Monthly Refereed Journal of Research in Management \& Technology, 4(1). Retrieved on February 11, 2020 from,

http://citeseerx.ist.psu.edu/viewdoc/download ?doi=10.1.1.977.1299\&rep=rep1\&type=pdf

Jayaraman, K. S., \& Priyadarshini, S. (2018). Indian scientists concerned over funding crisis. Nature India. Retrieved on November 11, 2019 from,

https://www.natureasia.com/en/nindia/article/ 10.1038/nindia.2018.116

Kolachi, N. A., \& Shah, H. A. (2013). BRICS Countries And Their Strategic HRD Agenda In 2020. International Journal of Management \& Information Systems (IJMIS), 17(2), 105-112. doi: https://doi.org/10.19030/ijmis.v17i2.7714

Lewis, D. (2017). Funding debate over paper quality vs quantity. Nature Index. Retrieved on December 2, 2019 from,

https://www.natureindex.com/news-

blog/funding-debate-over-paper-quality-vsquantity

McGinn, M. K. (2012). Being academic researchers: Navigating pleasures and pains in the current Canadian context. Workplace, 21, 14-24.

Meyer, N. P., \& Nascimento, M. (2014). Some trends in higher education and research in BRICS countries. In A. Bawa, N. Bohler-Muller, S. Fikeni, S. Zondi, \& S. Naidu (Eds.), Fifth BRICS academic forum Pretoria: Department of International Relations and Cooperation (pp. 117-133).

Minch, M. (2013). Higher Education and Research in India. International Journal of Social Science \& Interdisciplinary Research. Retrieved on October 1, 2019 from, http://indianresearchjournals.com/pdf/IJSSIR/2 013/March/10.pdf

Mullen, C. A., Murthy, U., \& Teague, G. (2008). Listening to those we serve: Assessing the research needs of university faculty. Journal of Research Administration, 39(1), 10-31.

Niemczyk, E. K. (2018). Developing globally competent researchers: International 
perspective. South African Journal of Higher Education, 32(4), 171-185. doi.

org/10.20853/32-4-1602

Odhiambo, N. M., \& Ntenga, L. (2015). Higher Education Research Expenditure in South Africa: A Review of the New Funding Framework. Industry and Higher Education, 29(4), 283-291. doi: https://doi.org/10.5367/ihe.2015.0263

Orlikowski, W. J., \& Baroudi, J. J. (1991). Studying Information Technology in Organizations: Research Approaches and Assumptions. Information Systems Research, 2(1), 1-28. doi:

https://doi.org/10.1287/isre.2.1.1

Panigrahi, J. (2019). Financing of Higher Education Institutions: Evidence from select case studies of universities in India. Arthika Charche: FPI Journal of Economics \& Governance. Retrieved from http://fpibangalore.gov.in/english/FPIJournal.asp

Patton, M. Q. (2014). Qualitative Research \& Evaluation Methods: Integrating Theory and Practice (4th ed.). Thousand Oaks, CA: Sage.

Prasad, R. (2015). Fake journals: 'Make in India' gone wrong. The Hindu. Retrieved from http://www.thehindu.com/sci-tech/fakejournals-make-in-indiagonewrong/article7800231.ece

Rajan, K. S., Swaminathan, S., \& Vaidhyasubramaniam, S. (2018). Research Output of Indian Institutions during 2011-2016: Quality and Quantity Perspective. Current Science, 114(4), 740-746. doi: $10.18520 / \mathrm{cs} / \mathrm{v} 114 / \mathrm{i04} / 740-746$

Reddy, S. (2018). The Growing BRICS Economies: An INET Series. Institute for New Economic Thinking. Retrieved on November 10, 2019 from, https://www.ineteconomics.org/perspectives/b $\mathrm{log} /$ the-growing-brics-economies-an-inet-series Roller, M. R., \& Lavrakas, P. J. (2015). Applied qualitative research design: A total quality framework approach. New York: Guilford Press.
Sesay, B., Yulin, Z., \& Wang, F. (2018). Does the national innovation system spur economic growth in Brazil, Russia, India, China and South Africa economies? Evidence from panel data. South African Journal of Economic and Management Sciences, 21(1), a1647. doi: https://doi.org/10.4102/ sajems.v21i1.1647

Smolentseva, A. (2015). The Idea of a Research University in Russia. International Higher Education, 47. doi: https://doi.org/10.6017/ihe.2007.47.7965 Sparkes, A. C. (2007). Embodiment, academics, and the audit culture: A story seeking consideration. Qualitative Research, 7, 521-550. doi: https://doi.org/10.1177/1468794107082306

Wang, D. (2019). Performance-based resource allocation for higher education institutions in China. Socio-Economic Planning Sciences, 65(C), 66-75. doi: 10.1016/j.seps.2018.01.004

Wolhuter, C. (2019). The Salience of African Scholars in Education Research. Africa Education Review, 16(1), 142-157, doi: 10.1080/18146627.2016.1241669

Wolhuter, C. (2008). Review of the Review: Constructing the Identity of Comparative Education. Research in Comparative and International Education, 3(4): 323-344.

World Bank. (1998). World Development Report 1998/199: Knowledge for Development. New York: Oxford University Press. Retrieved on January 12, 2020 from, https://openknowledge.worldbank.org/handle/ 10986/5981

Zinurova, R. I., Berman, S. S., Tuzikov, A. R., Gayazova, E. B., Stayzhkina, E. I., Medvedeva, V. R., \& Frolova, I. A. (2016). The management of Russian universities on the basis of international education quality standards. 6 . 204-211.

Xie, Q., \& Freeman, R. B. (2019). Bigger than You Thought: China's Contribution to Scientific Publications and its Impact on the Global Economy. China \& World Economy, 27(1), 1-27. doi: http://dx.doi.org/10.1111/cwe.12265 